\title{
The Influence of Seasonal Variation of Thermal Variables on Comfort Temperature in Schools in a Warm and Humid Climate
}

\author{
Charles Munonye \\ Department of Architecture Chukwuemeka Odumegwu Ojukwu University, Anambra State, Nigeria \\ Email:cc.munonye@coou.edu.ng
}

How to cite this paper: Munonye, C. (2020) The Influence of Seasonal Variation of Thermal Variables on Comfort Temperature in Schools in a Warm and Humid Climate. Open Access Library Journal, 7: e6753. https://doi.org/10.4236/oalib.1106753

Received: August 26, 2020

Accepted: September 27, 2020

Published: September 30, 2020

Copyright $\odot 2020$ by author(s) and Open Access Library Inc.

This work is licensed under the Creative Commons Attribution International License (CC BY 4.0).

http://creativecommons.org/licenses/by/4.0/

\begin{abstract}
This study aims to examine the influence of seasonal variations of thermal variables on comfort temperature in schools in a warm and humid climate. Schoolchildren in Nigeria are engaged in in-class lessons in the two seasons experienced in the country. There have been concerns about whether seasonal variation in thermal variables can affect the thermal comfort of building occupants. To address this issue, data were collected from 180 healthy primary schoolchildren aged 7 - 12 years old. The research methodology consisted of measuring environmental variables, while questionnaires were applied to the children during the rainy season and dry season. The result shows some significant seasonal differences in the measured thermal variables and comfort temperature. The mean indoor temperature observed during the dry season was $29.1^{\circ} \mathrm{C}$ while during the rainy season the mean value was $28.1^{\circ} \mathrm{C}$. The subjects found the indoor environment acceptable during the rainy season, while during the dry season it was found unacceptable. Furthermore, differences in neutral temperature and comfort range between seasons were observed. Architects and facility managers need to have information about thermal conditions in schools according to season. This is because primary schoolchildren are vulnerable, and exposing them to variations in indoor temperature may impact on their health and academic performance.
\end{abstract}

\section{Subject Areas}

Architecture

\section{Keywords}

Architects, Facility Managers, Schoolchildren, Seasonal Variation, Thermal Comfort, Thermal Variables 


\section{Introduction}

Indoor environments are expected to provide thermal comfort to the occupants. Thermal comfort is defined by the American Society of Heating, Refrigerating, and Air Conditioning Engineers (ASHRAE) as the "condition of mind that expresses satisfaction with the thermal environment" [1]. In most studies, thermal comfort is rated as the number one component of the Indoor Environmental Quality (IEQ) that gives building occupants the most concern to comfortable living [2]. Various studies have related the effect of high temperatures on health issues. Exposure to high temperatures can cause health problems such as an increased risk of heatstroke, respiratory and cardiovascular hospitalizations, and deaths [3] [4]. Primary school buildings in Nigeria constitute a significant portion of the building sector where people stay over a long period. The indoor environments of classrooms are vital for pupils' perception, health, and academic performance [5]. In Nigeria, there are two school systems; public school and private school. The private schools are owned by the government and consist of two typical design types, while the private schools come in various architectural designs and some of them are air-conditioned. All the public primary schools in the area are naturally ventilated and none has any air-conditioning system. However, because of the continuous increase in global surface temperature, there is a likelihood that this use of air-conditioning systems to provide thermal comfort may be extended to the public schools which, for now, solely depend on natural infiltration of air into the classrooms. In Nigeria, the use of artificial devices such as air conditioners has increased. The amount of energy consumption and expense required to maintain these systems is very high. There is evidence that artificially conditioned spaces have a high level of thermal rejection by their occupants, especially environments with central air systems [6] [7]. Providing the needed thermal comfort in buildings using active ventilators means more energy consumption for which the building sector contributes $19 \%-50 \%$ with the likely outcome of rising to $60 \%$ in future [8].

Some researchers argue that adopting and generalizing the current thermal comfort standard, adopted from a field study on adults, and applying them on children may give wrong feedbacks as to what the actual thermal comfort conditions of children are [9]. Various studies have shown that the temperature of thermal comfort for young children may differ from that of adults [10] [11]. Children have different metabolic rates and activity levels when compared to that of adults [9] [12]. There are reports of building occupants in Nigeria finding the indoor environments unacceptable. However, all the studies conducted in Nigeria were based on surveys conducted in residential buildings and offices, and the surveys were mostly carried out in one season [e.g., [13] [14] [15]], while other studies were carried out in one month [e.g. [16]]. Furthermore, all the thermal comfort studies conducted in Nigeria used only adults in their evaluation. There is a dearth of studies that used children in these evaluations of thermal comfort in buildings in Nigeria, and limited information about thermal 
comfort in schools according to season.

Various research works showed some seasonal variations in indoor environments and thermal perception of building occupants. [17] conducted a study of ventilation and thermal comfort of NV classrooms in the Gaza strip climate. The results showed significant seasonal variations in the perceived indoor environment and thermal comfort in the monitored schools. [18] conducted a study to examine human responses to the seasonal variations of indoor thermal environment in China. Results show a significant difference in adaptive responses in different seasons. This study aims to obtain information about the thermal variables and the subjects' thermal perceptions for different seasons in NV classrooms. This will provide fundamental knowledge of the thermal comfort demand for primary school buildings in the region.

\section{Survey Methods}

\subsection{Subjects}

The surveyed classrooms were visited 163 times in both seasons covering both the morning and afternoon periods. The rainy season survey was carried out from October 12 to Nov 3 and from May 9 to May 29 totaling 63 visits. The dry season survey was carried from January 15 to 31, from February 6 to 28 and from April 2 to 31. The dry season survey period totaled 100 visits. The questionnaires were drawn from 180 healthy primary schoolchildren aged $7-12$ years during the rainy season and dry season surveys. Table 1 shows that a set of 85 , representing $47.2 \%$ of the children participated during the dry season survey, while 95 children, representing 52.8\%, participated during the rainy season survey. Further details show that the number of female participants was more (61.1\%) compared to the male (38.9\%) during both seasons. According to the season, females constituted: $62.1 \%$ and $60.0 \%$ for the rainy season and the dry

Table 1. Summary of the subjects in the surveyed classrooms.

\begin{tabular}{|c|c|c|c|c|c|c|c|}
\hline & & \multicolumn{2}{|c|}{$\begin{array}{c}\text { Total } \\
(\mathrm{n}=180)\end{array}$} & \multicolumn{2}{|c|}{$\begin{array}{l}\text { Dry season } \\
\quad(\mathrm{n}=85)\end{array}$} & \multicolumn{2}{|c|}{$\begin{array}{l}\text { Rainy season } \\
\quad(\mathrm{n}=95)\end{array}$} \\
\hline & & $\begin{array}{l}\text { Sample } \\
\text { size }\end{array}$ & Percentage & $\begin{array}{l}\text { Sample } \\
\text { size }\end{array}$ & Percentage & $\begin{array}{l}\text { Sample } \\
\text { size }\end{array}$ & Percentage \\
\hline \multirow{3}{*}{ Gender } & Male & 70 & $38.9 \%$ & 34 & $40.0 \%$ & 36 & $37.9 \%$ \\
\hline & & & & & & & \\
\hline & Female & 110 & $61.1 \%$ & 51 & $60.0 \%$ & 59 & $62.1 \%$ \\
\hline \multirow{5}{*}{$\begin{array}{c}\text { Age } \\
\text { (years) }\end{array}$} & $<7$ & 0 & $0 \%$ & 0 & $0 \%$ & 0 & $0 \%$ \\
\hline & $7-8$ & 13 & $7.2 \%$ & 7 & $54.0 \%$ & 6 & $46.0 \%$ \\
\hline & $9-10$ & 92 & $51.1 \%$ & 44 & $47.8 \%$ & 48 & $52.2 \%$ \\
\hline & $11-12$ & 75 & $41.7 \%$ & 34 & $45.3 \%$ & 41 & $54.7 \%$ \\
\hline & $>12$ & 0 & $0 \%$ & 0 & $0 \%$ & 0 & $0 \%$ \\
\hline
\end{tabular}


season, respectively, against $37.9 \%$ and $40.0 \%$ for the rainy season and dry season respectively for men. Most of the participating children (51.1\%) were within the age range of 9 - 10 years, with 9 years as the mean age. Of all the participants that were surveyed, none was less than 7 years or more than 12 years. A majority of them (96\%) was born in the study area (Imo state) and have lived in the state throughout their life.

\subsection{Data Collection}

A longitudinal design approach was used to survey the subjects repeatedly in the two seasons in the present study. A purposive sampling technique was adopted to select each of the surveyed schools from the three zones that make up the survey state (Imo State). In each of these schools, two classrooms were selected for the survey. For homogeneity in the age range of the surveyed students, the surveys were carried out in class five and class six in each of the schools. The objective surveys were carried out to record the thermal environmental parameters in the six selected NV classrooms of the same architectural characteristics. Tinytag Ultra 2 (TGU-4500) and TinyTag 2 (TGP-4017) were used to record data every five minutes from each of the surveyed classrooms. For the outdoor temperature, Tinytag Plus 2 (TGP-4500) did the recording and both loggers had a temperature reading resolution of $\pm 0.01^{\circ} \mathrm{C}$, while the reading resolution of the relative humidity was $\pm 0.3 \%$. The instruments used for the survey met the prescriptions of ASHRAE Standard 55 and were often adopted by some thermal comfort researchers because of their reliability. The outdoor data logger was adequately shaded from rain and sunlight. It has a built-in temperature sensor, 32,000 reading capacity, a delayed start option, and a high reading resolution and user program alarm.

Kestrel 3000 Pocket Wind Meter recorded the indoor air velocity. The indoor data loggers were carefully positioned in the surveyed classrooms to ensure they did not prevent the children and their teachers from walking around the classrooms freely.

During the morning survey, the questionnaires were distributed and filled at $9.00 \mathrm{am}$. At that time, the students were either reading or writing and most had entered the classroom about an hour before this time. The adaptation time in this survey was set at 60 minutes within which the metabolic rates of the subjects were assumed to have settled and reached the recommended sedentary level of 1.2 met, which corresponds to light office activity in the ASHRAE Handbook of fundamentals. The ASHRAE adaptive comfort applies to spaces where the occupants are engaged in near sedentary physical activities with metabolic rates ranging from 1.0 to 1.3 [1].

The subjective measurements were carried out to collect the students' responses to the thermal environmental conditions. A commonly used thermal comfort questionnaire was adopted to obtain comprehensive information on the children's responses to the thermal environment. Thermal sensation, comfort 
temperature, and acceptability are the most important human responses to thermal environments, and their relationships to a large extent determine the definitions of optimal conditions and acceptable ranges [19]. Subjects thermal sensation votes use the ASHRAE seven-point thermal sensation scale ( -3 cold to +3 hot) with neutral in the middle. The three-point thermal preference scale asked the respondents whether they would prefer the thermal environment to remain the way they met it or whether they prefer the condition to change. Possible responses were "want warmer", "no change" or "want cooler". The subjects' were required to fill the questionnaire twice a day: morning hours at 9.00 am and afternoon hours at $1.00 \mathrm{pm}$. These two periods were selected as they represented the coolest and warmest conditions of the school period. As the questionnaires were being filled, the data loggers were simultaneously measuring the environmental parameters.

\section{Results and Discussion}

A check at the surveyed classrooms before the commencement of the survey showed that there were no heating objects in the spaces. The classrooms enjoyed adequate shading from the sun. Furthermore, spot measurements taken at the various locations in the classrooms produced negligible differences in air temperature. Also, the mean clo value of the studied school children was 0.5 while the air velocity did not exceed $0.2 \mathrm{~m} / \mathrm{s}$. As a result of these observations, the Mean Radiant Temperature (MRT) was assumed to be equal to Air Temperature (AT). The operative temperature was adopted as an index for the analysis in this study. The statistical results of the environmental data and the analysis are presented in the subsequent sections.

\subsection{Seasonal Variability}

The measured thermal variables included air temperature, relative humidity, and air velocity for the physical evaluation of the indoor environment. The twelve months in a year are divided into two seasons: rainy season (which includes the months of May, June, and October) and dry season (which includes the months of January, Feb, and March). The adaptive comfort model suggests that in NV buildings the indoor temperature fluctuates with the outdoor temperature. Results of the environmental parameters shown in Table 2 indicate that during the rainy season and dry season, the indoor operative temperature ranged between $24^{\circ} \mathrm{C}$ to $34.7^{\circ} \mathrm{C}$ and between $24.8^{\circ} \mathrm{C}$ to $35.6^{\circ} \mathrm{C}$, respectively. The indoor relative humidity ranged between $28.2 \%$ to $86.9 \%$ and between $25.6 \%$ to $86.2 \%$ during the rainy season and dry season, respectively. The results show that the range of indoor temperatures and the relative humidity observed in this study differ according to season. These ranges of thermal variables also exceeded the ranges specified by the international standards. The comfort temperature specified by the standard (for summer) for sedentary activity is between $26^{\circ} \mathrm{C}-28^{\circ} \mathrm{C}$ [20] and for the $\mathrm{RH}$ between $30 \%$ and $70 \%$. Furthermore, during the rainy season, 
Table 2. Statistical results of the variables.

\begin{tabular}{ccccccc}
\hline & \multicolumn{3}{c}{ Rainy season } & \multicolumn{3}{c}{ Dry season } \\
\cline { 2 - 7 } Parameters & Mean & Min & Max & Mean & Min & Max \\
\hline Indoor air temperature $\left({ }^{\circ} \mathrm{C}\right)$ & 28.1 & 24.0 & 34.7 & 29.1 & 24.8 & 35.6 \\
Outdoor temperature $\left({ }^{\circ} \mathrm{C}\right)$ & 28.9 & 23.0 & 35.6 & 29.2 & 24.0 & 37.4 \\
Indoor relative humidity (\%) & 73.8 & 28.2 & 86.9 & 70.5 & 25.6 & 86.2 \\
Indoor air velocity $(\mathrm{m} / \mathrm{s})$ & 0.19 & - & - & 0.14 & - & - \\
\hline
\end{tabular}

the range of indoor operative temperature $(\mathrm{OT})$ was higher $\left(12.3^{\circ} \mathrm{C}\right)$ compared to the range during the dry season $\left(9.2^{\circ} \mathrm{C}\right)$. A lower value in indoor operative temperature $\left(\mathrm{T}_{\mathrm{OP}}\right)$ was observed during the rainy season, while a higher value was observed during the dry season. The range of outdoor temperature was, however, higher during the dry season compared to the rainy season. The indoor operative temperatures were generally lower than the outdoor temperatures.

\subsection{Seasonal Variation in Temperature}

Figure 1 shows that temperatures in the range between $28^{\circ} \mathrm{C}-30^{\circ} \mathrm{C}$ were more frequent in the surveyed classrooms during the survey periods. Comparing the two seasons, $48 \%$ of indoor temperatures in this range were observed during the dry season while during the rainy season temperatures in this range were observed $34 \%$ of the survey period. This suggests that the surveyed schoolchildren encountered temperatures within this range $14 \%$ of the time more during the dry season compared to the rainy season survey. The total frequency of observed temperatures in the range from $28^{\circ} \mathrm{C}-32^{\circ} \mathrm{C}$ during the rainy season was $56 \%$ and $68 \%$ during the dry season. This further suggests that the subjects encountered warmer indoor conditions during the dry season compared to the rainy season. Considering the frequency of occurrence of indoor lower temperatures, higher frequency in the temperature range from $24^{\circ} \mathrm{C}$ $26^{\circ} \mathrm{C}$ was encountered by the subjects during the rainy season compared to the dry season.

\subsection{Seasonal Variation in Thermal Sensation and Preference}

The result of the thermal sensation votes of the subjects shows that the children felt cold during the rainy season having expressed, through voting, a mean thermal sensation of -0.11 . The voting is slightly above neutral (okay) which is an indication that the subjects were comfortable with the indoor thermal conditions. The expressed thermal sensation is consistent with the voting on the ASHRAE scale where $83.1 \%$ of the subjects voted within the three central categories during the rainy season. This suggests that the subjects were satisfied with the indoor conditions. ASHRAE standard 55 specified that an acceptable thermal 


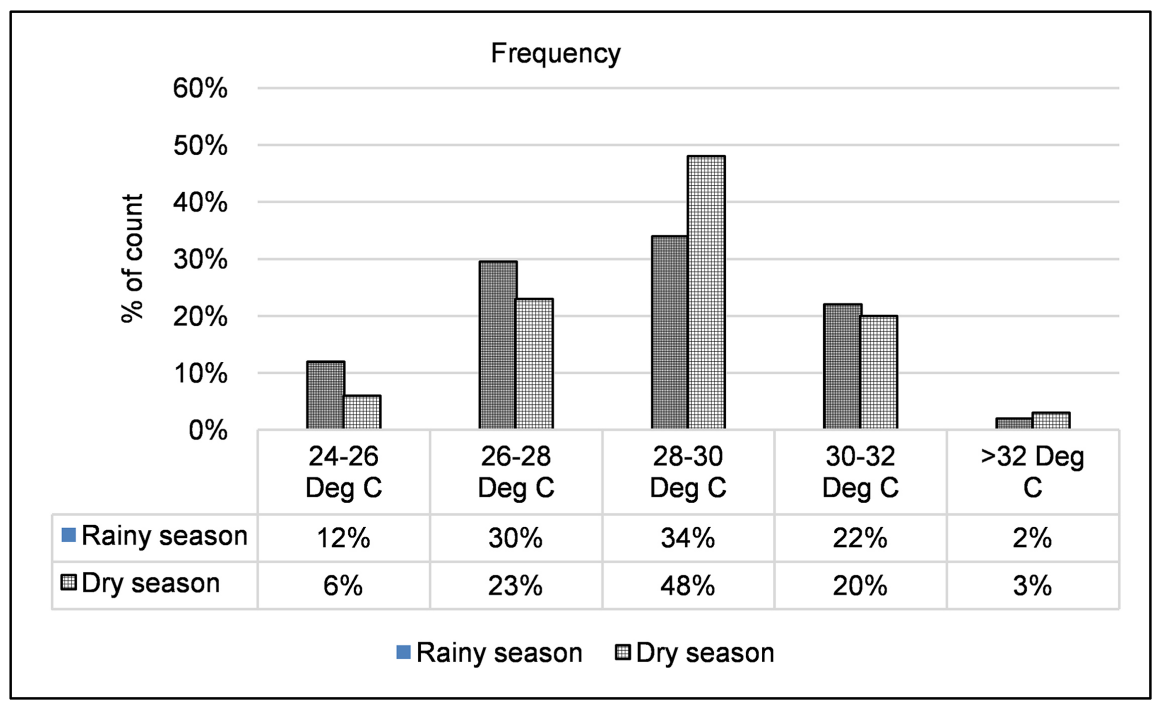

Figure 1. Frequency distribution of range of indoor temperature according to season.

environment should have $80 \%$ of occupant's votes falling within the three categories $(-1,0,+1)$. During the dry season, $73.5 \%$ of the subjects voted within the three central categories at a mean thermal sensation of +0.45 . By this mean thermal sensation, the subjects expressed the environment to be warm. Thus, voting $73.5 \%$ is an indication that they did not accept the indoor thermal environment according to the requirements of ASHRAE standard 55. Figure 2 further shows that the highest percentage of the subjects indicated neutrality irrespective of the season. Near to half of the entire class in both seasons indicated that the classrooms were neither "too cold" nor "too warm" (0). Though, a higher percentage of the children voted on neutrality during the dry season compared to the voting on neutrality by the same subjects during the rainy season.

Almost the same number of subjects who said they were okay (42.3\%) with their thermal conditions during the rainy season said they prefer no change (50\%). However, there was a significant shift in the voting during the dry season where almost $30 \%$ of the subjects who voted okay in thermal sensation would prefer another thermal state.

The results of the subjective thermal preference amongst the respondents are presented in Figure 3. The percentage of the studied school children who prefer a cooler indoor environment was significantly higher during the dry season (79\%) compared to the rainy season (30\%). This is consistent with the result of the thermal sensation where a higher percentage of the students felt warmer during the dry season compared to the rainy season. Furthermore, half of the subjects prefer the indoor environment to remain the way they met it during the rainy season, while only $17 \%$ of the same class would prefer it to remain the way they met it during the dry season. The relative frequency distribution of preference vote had a "bias" towards the "cooler" side of the scale. A lower percentage of the class prefers a warmer environment, irrespective of the season. 


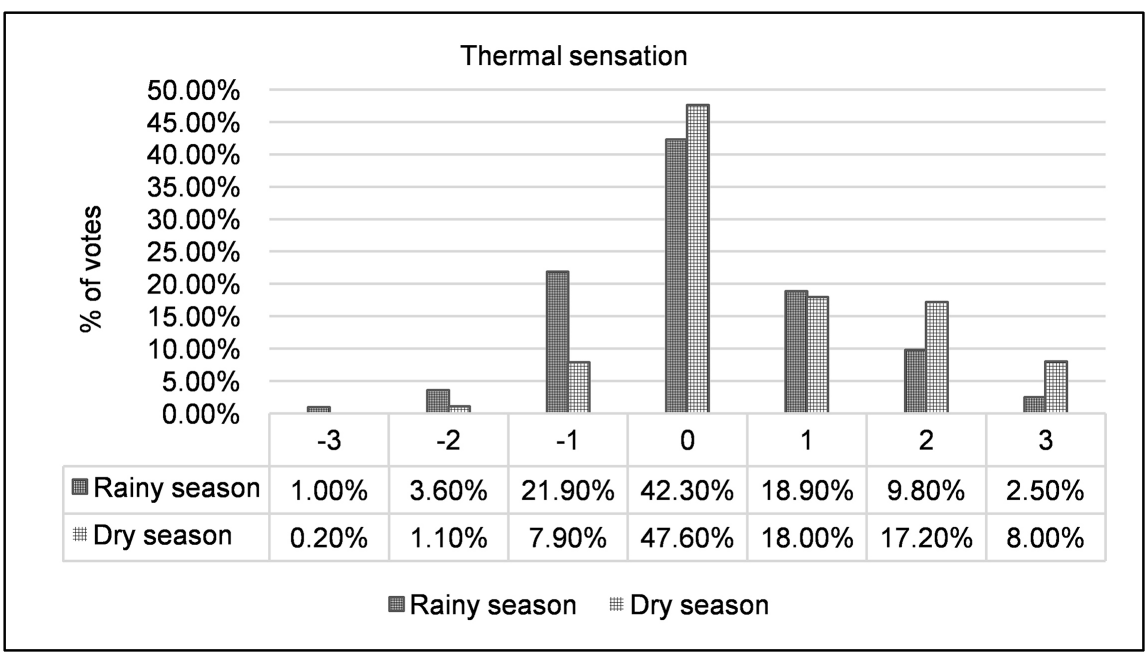

Figure 2. Thermal sensation votes.

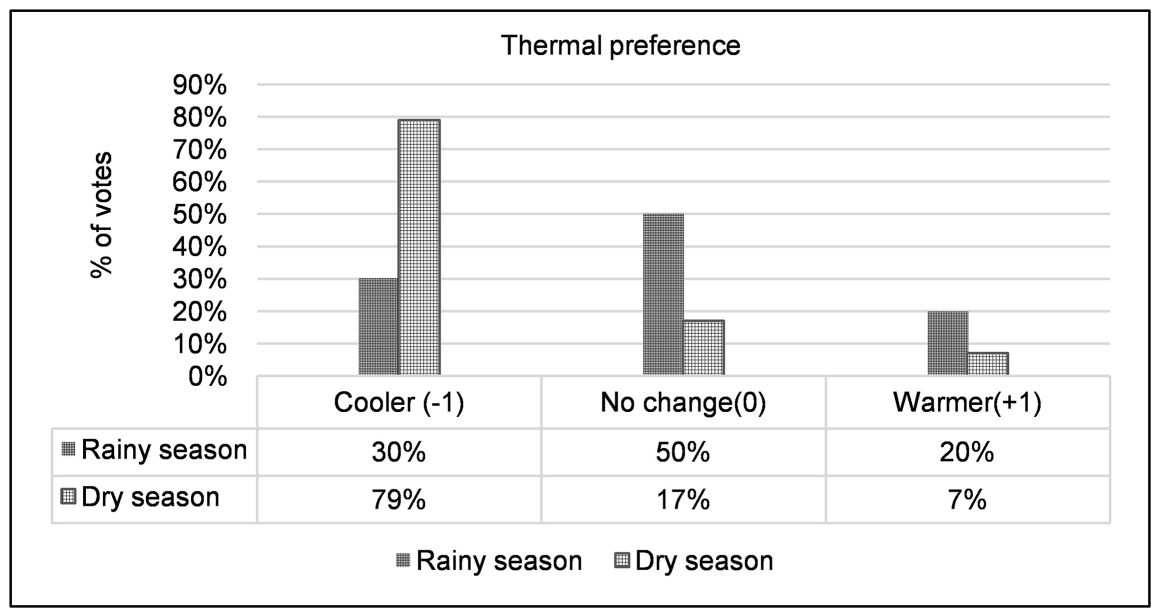

Figure 3. Thermal preference vote.

\subsection{Seasonal Variation in Neutral Temperature and Sensitivity}

Neutral temperature, a product of the relationship between thermal sensation votes and the indoor operative temperatures can be determined through linear regression analysis. Linear regression is popularly used to determine the trend of the mean response of a group of people over the range of temperatures they encounter [21]. This is on the assumption that the comfort votes and the temperatures are dependent and independent variables, respectively [22]. The relationship between the young children's thermal sensation and the indoor operative temperatures of the classrooms were examined through linear regression analysis. This revealed the children's thermal behaviour in the classrooms, and how they respond to the variabilities in the classrooms.

To determine the neutral temperature $\left(\mathrm{T}_{\mathrm{n}}\right)$ of the studied children, the classroom's mean indoor temperature together with the mean thermal sensation of the subjects, for each visit made to the classrooms, was calculated. The calculation of the neutral temperature was obtained from the regression equation de- 
rived by using Microsoft Office Excel version 16. The statistical test was analyzed using SPSS version 17. The approach employed in ASHRAE adaptive comfort standard was used to define the indoor operative comfort range, which defines the $80 \%$ operative comfort range as $-0.85 \leq \mathrm{TSV} \leq+0.85$ [23]. This corresponds to approximately $80 \%$ thermal satisfaction, where the Predicted Percentage of Dissatisfied (PPD) is less than $20 \%$. The neutral temperature corresponding to TSV value equaling " 0 ” was also calculated.

The regression of the mean responses of the young children (mean thermal sensation votes) upon the mean indoor operative temperature in the studied schools during the rainy season and dry season (shown in Figure 4) produced the regression Equations (1) and (2), respectively.

$$
\begin{array}{ll}
\mathrm{TSV}=0.29 \mathrm{~T}_{\mathrm{OP}}-8.44\left(\mathrm{R}^{2}=0.629\right) & \text { Rainy } \\
\mathrm{TSV}=0.17 \mathrm{~T}_{\mathrm{OP}}-4.64\left(\mathrm{R}^{2}=0.2094\right) & \text { Dry }
\end{array}
$$

Based on the predicted mean votes (PMV), a neutral temperature $29.1^{\circ} \mathrm{C}$ was obtained from the regression Equation (1) for the rainy season, while neutral temperature of $27.3^{\circ} \mathrm{C}$ was obtained from regression equation ii for the dry season. This suggests that the subjects expressed higher neutral temperature during the rainy season compared to the dry season.

The regression slope is a measure of sensitivity to temperature changes [23]. The gradient of regression equation for linear models is inversely proportional to the adaptability of the building occupants [10]. A shallow gradient indicates that subjects adapt more effectively to temperature changes. Children's adaptability to temperature changes is higher during the dry season because the slope is shallower (0.17) than that of rainy season (0.29) as shown in regression Equations (1) and (2). In order words, during the rainy season the children will experience a 1 unit change (eg from 0 to +1 ) in their thermal state for every $3.4^{\circ} \mathrm{C}$ (inverse of 0.29 ) change in operative temperature. During the dry season, the same subjects will experience a 1 unit change in their thermal state for every $5.9^{\circ} \mathrm{C}$ in operative temperature. In comparison, the students' sensitivity to temperature variation in the rainy season is almost twice than in the dry season. The high sensitivity to temperature changes expressed during the rainy season
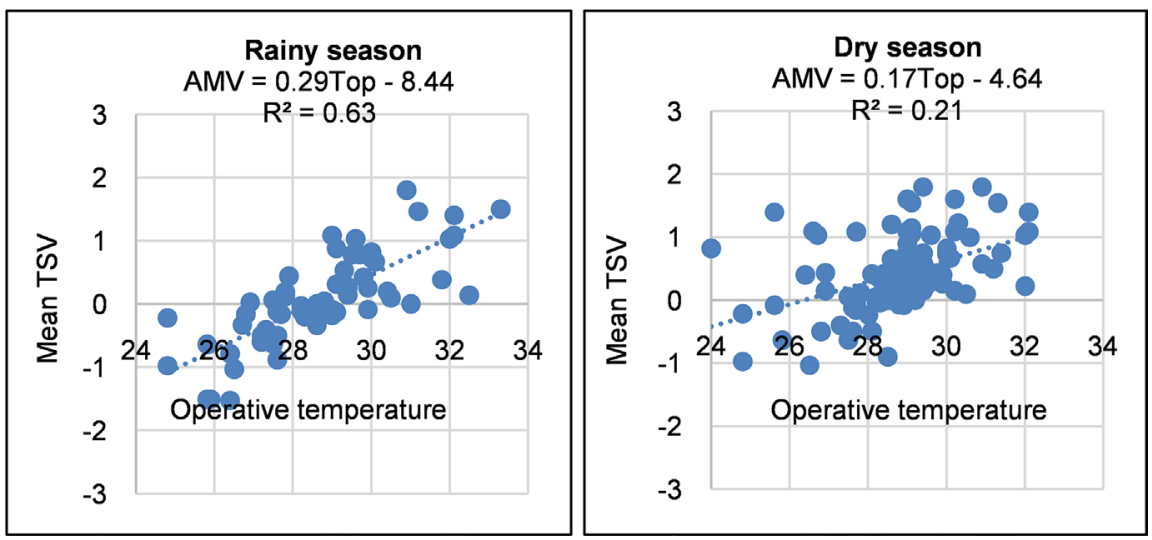

Figure 4. Regression analysis of thermal sensation against $\mathrm{T}_{\mathrm{op}}$. 
appears to be as a result of poor behavioral adaptation to thermal environment. During the rainy season, especially in the morning hours when the weather was generally cold and during the rains, it was observed that the students were not very free to put on extra clothing to ward off the cold weather.

\subsection{Seasonal Variation in Comfort Range and Comfort Votes}

The breakdown of comfort range according to season showed that in the rainy season, the comfort range was between $26.2^{\circ} \mathrm{C}-32.0^{\circ} \mathrm{C}$ while in the dry season, the range was between $22.3^{\circ} \mathrm{C}-32.3^{\circ} \mathrm{C}$, considering the $80 \%$ ASHRAE Standard 55 comfort zone $( \pm 0.85)$. The upper limit of the comfort range during the dry season is slightly higher than the upper limit during the rainy season. Furthermore, the comfort bandwidth is wider during the dry season compared to the rainy season. The result suggests that the studied children were adapted to the higher and a wider range of indoor temperatures during the dry season compared to the rainy season. Furthermore, Figure 5 shows that the subject's comfort votes on "comfortable" at the indoor temperature range that prevailed most in the classrooms $\left(28^{\circ} \mathrm{C}-30^{\circ} \mathrm{C}\right)$ was $63 \%$ in the rainy season survey, while in the dry season survey the vote was $60 \%$. This suggests that the percentage of subjects who found the indoor condition comfortable were slightly more during the rainy season compared to the percentage during the dry season.

\subsection{Seasonal Variation in Thermal and Humidity Acceptability}

More of the children accepted the prevailing indoor thermal conditions during the rainy season compared to the dry season. As shown in Figure 6, while the acceptability was $64 \%$, during the rainy season, $62 \%$ in the surveyed children accepted the thermal conditions during the dry season survey. $84 \%$ of the sampled population accepted the $\mathrm{RH}$ during the rainy season survey, close to the same number (81\%) that accepted the RH during the dry season.

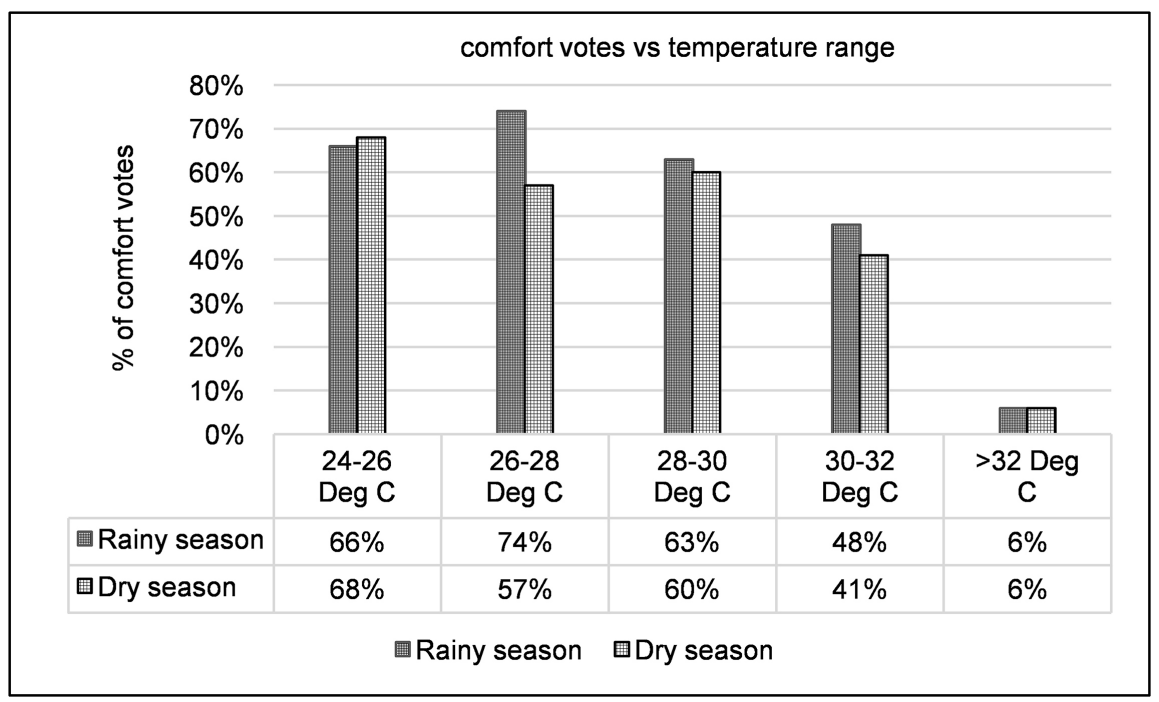

Figure 5. Frequency distribution of range of indoor temperature with respect to comfort votes according to season. 


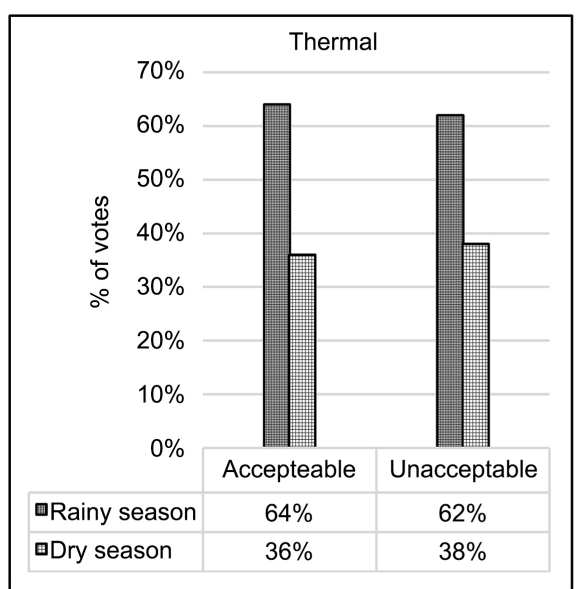

(a)

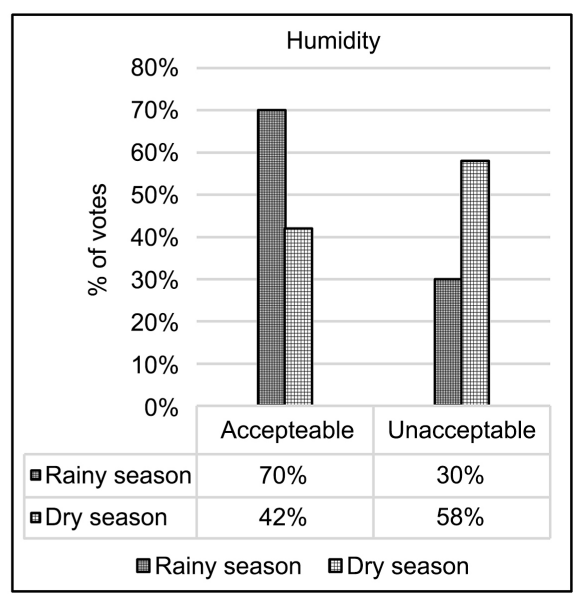

(b)

Figure 6. Thermal comfort acceptability (a) and relative humidity acceptability (b).

\section{Conclusion}

Children spend a considerable part of their day in classrooms, hence understanding the thermal conditions in these indoor spaces is important because of health and academic concerns. It is also important to categorize the thermal conditions according to the season to guide designers and facility managers. During the dry season and rainy season, the recorded mean indoor temperatures were $29.1^{\circ} \mathrm{C}$ and $28.1^{\circ} \mathrm{C}$, respectively. Temperatures in the range between $28^{\circ} \mathrm{C}$ $30^{\circ} \mathrm{C}$ occurred most frequently for $34 \%$ of the time during the rainy season and $48 \%$ of the time during the dry season. While half of the class preferred the thermal condition to remain the way they met it during the rainy season, only $17 \%$ of the same class during the dry season preferred the thermal state to remain the way they met it. A higher neutral temperature was observed during the rainy season compared to the neutrality obtained during the dry season, only $17 \%$ of the same class during the dry season preferred the thermal state to remain the way they met it. A higher neutral temperature was observed during the rainy season compared to the neutrality obtained during the dry season. Another important finding is that the studied children were more sensitive to temperature changes during the rainy season compared to the dry season.

\section{Conflicts of Interest}

The author declares no conflicts of interest regarding the publication of this paper.

\section{References}

[1] Ashrae, A. (2017) Standard 55-2017. Thermal Environmental Conditions for Human Occupancy.

[2] Munonye, C. and Ji, Y.C. (2017) Rating the Components of Indoor Environmental Quality in Students Classrooms in Warm Humid Climate of Uli, Nigeria. 13th International Postgraduate Research Conference, University of Salford, 14-15 Sep- 
tember 2017, 902.

[3] Anderson, G.B., Dominici, F., Wang, Y., McCormack, M.C., Bell, M.L. and Peng, R.D. (2013) Heat-Related Emergency Hospitalizations for Respiratory Diseases in the Medicare Population. American Journal of Respiratory and Critical Care Medicine, 187, 1098-1103. https://doi.org/10.1164/rccm.201211-1969OC

[4] Hoshiko, S., English, P., Smith, D. and Trent, R. (2010) A Simple Method for Estimating Excess Mortality Due to Heat Waves, as Applied to the 2006 California Heat Wave. International Journal of Public Health, 55, 133-137. https://doi.org/10.1007/s00038-009-0060-8

[5] Jiang, J., Wang, D.J., Liu, Y.F., Xu, Y.C. and Liu, J.P. (2018) A Study on Pupils' Learning Performance and Thermal Comfort of Primary Schools in China. Building and Environment, 134, 102-113. https://doi.org/10.1016/j.buildenv.2018.02.036

[6] Nogueira, B.L. (2018) Evaluation of Thermal Comfort in Commercial Buildings Operating under Mixed Environmental Conditioning Systems in Temperate and Humid Climate [In Portuguese-Percepção e reação de trabalhadores ao ambiente térmico em escritórios condicionados artificialmente no ocntexto do clima quente e úmido]. Master's Thesis, Federal University of Paraíba, Joao Pessoa.

[7] Souza, J., Nogueira, B., Limsa, A. and Leder, S. (2020) Thermal Comfort Analysis in Both Naturally Ventilated and Air-Conditioned Classrooms in a Warm and Humid Climate. IOP Conference Series: Earth and Environmental Science, Temuco, Chile, 16-18 October 2019. https://doi.org/10.1088/1755-1315/503/1/012044

[8] López-Pérez, L.A., Flores-Prieto, J.J. and Ríos-Rojas, C. (2019) Adaptive Thermal Comfort Model for Educational Buildings in a Hot-Humid Climate. Building and Environment, 150, 181-194. https://doi.org/10.1016/j.buildenv.2018.12.011

[9] Zomorodian, Z.S., Tahsildoost, M. and Hafezi, M. (2016) Thermal Comfort in Educational Buildings: A Review Article. Renewable and Sustainable Energy Reviews, 59, 895-906. https://doi.org/10.1016/j.rser.2016.01.033

[10] De Dear, R. and Brager, G.S. (1998) Developing an Adaptive Model of Thermal Comfort and Preference. Center for the Built Environment, Berkeley.

[11] Trebilcock, M., Soto-Munoz, J., Yanez, M. and Figueroa-San Martin, R. (2017) The Right to Comfort: A Field Study on Adaptive Thermal Comfort in Free-Running Primary Schools in Chile. Building and Environment, 114, 455-469. https://doi.org/10.1016/j.buildenv.2016.12.036

[12] Jiang, J., Wang, D., Liu, Y., Xu, Y. and Liu, J. (2018) A Study on Pupils' Learning Performance and Thermal Comfort of Primary Schools in China. Building and Environment, 134, 102-113.

[13] Adaji, M., Watkins, R. and Adler, G. (2017) Indoor Thermal Comfort of Residential Buildings in the Hot-Humid Climate of Nigeria during the Dry Season. PLEA, Edinburgh, 3-5 July 2017.

[14] Ogbonna, A.C. and Harris, D.J. (2008) Thermal Comfort in Sub-Saharan Africa: Field Study Report in Jos-Nigeria. Applied Energy, 85, 1-11.

https://doi.org/10.1016/j.apenergy.2007.06.005

[15] Akingbade, F.O.A. (2004) Responses on Indoor Thermal Environment in Selected Dwellings during the Hot Season in Ibadan, Nigeria. Global Journal of Pure and Applied Sciences, 10, 627-633. https://doi.org/10.4314/gjpas.v10i4.16449

[16] Adunola, A.O. and Ajibola, K. (2016) Factors Significant to Thermal Comfort within Residential Neighborhoods of Ibadan Metropolis and Preferences in Adult Residents' Use of Spaces. SAGE Open, 6, 1-19. 
https://doi.org/10.1177/2158244015624949

[17] Elbayoumi, M., Ramli, N.Z., Yusof, N.F.F. and Al Madhoun, W. (2015) Seasonal Variation in School's Indoor Air Environments and Health Symptoms among Students in an Eastern Mediterranean Climate. Human and Ecological Risk Assessment, 21, 184-204. https://doi.org/10.1080/10807039.2014.894444

[18] Liu, H., Wu, Y.X., Li, B.Z., Cheng, Y. and Yao, R.M. (2017) Seasonal Variation of Thermal Sensations in Residential Buildings in the Hot Summer and Cold Winter Zone in China. Energy and Buildings, 140, 9-18. https://doi.org/10.1016/j.enbuild.2017.01.066

[19] Zhang, Y.F., Wang, J.Y., Chen, H.M., Zhang, J. and Meng, Q.L. (2010) Thermal Comfort in Naturally Ventilated Buildings in Hot-Humid Area of China. Building and Environment, 45, 2562-2570. https://doi.org/10.1016/j.buildenv.2010.05.024

[20] Appah-Dankyi, J. and Koranteng, C. (2012) An Assessment of Thermal Comfort in a Warm and Humid School Building at Accra, Ghana. Advances in Applied Science Research.

[21] Nicol, F., Humphreys, M. and Roaf, S. (2012) Adaptive Thermal Comfort: Principles and Practice. Routledge, Abingdon. https://doi.org/10.4324/9780203123010

[22] Haddad, S. (2016) Thermal Comfort in Naturally Ventilated Schools. A Field Study of Thermal Comfort in Iranian Primary School Classrooms. The University of New South Wales, Sydney.

[23] Humphreys, M.A. and Hancock, M. (2007) Do People Like to Feel "Neutral"?: Exploring the Variation of the Desired Thermal Sensation on the ASHRAE Scale. Energy and Buildings, 39, 867-874. https://doi.org/10.1016/j.enbuild.2007.02.014 